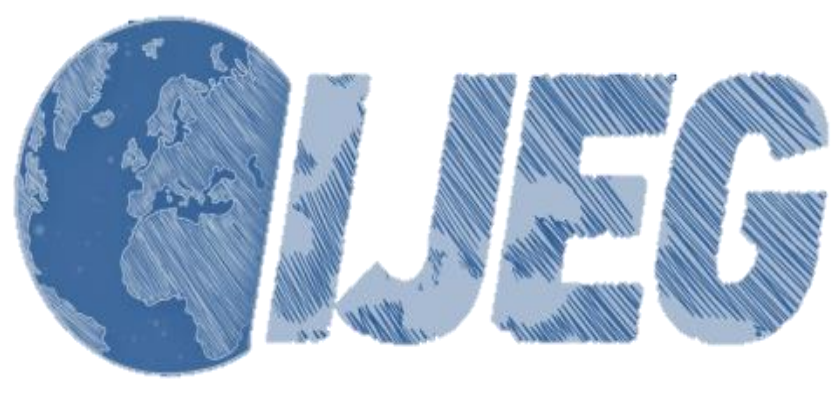

International Journal of Engineering and Geosciences (IJEG), Vol; 5, Issue; 3, pp. 120-129, October, 2020, ISSN 2548-0960, Turkey, DOI: 10.26833 ijeg. 638669

\title{
OPPORTUNITIES PROVIDED BY REMOTE SENSING DATA FOR WATERSHED MANAGEMENT: EXAMPLE OF KONYA CLOSED BASIN
}

\author{
Nur Yagmur ${ }^{1 *}$, Aysegul Tanik ${ }^{2}$, Aylin Tuzcu ${ }^{1}$, Nebiye Musaoglu ${ }^{1}$, Esra Erten ${ }^{1}$, Baha Bilgilioglu ${ }^{3}$ \\ ${ }^{1}$ ITU, Civil Engineering Faculty, Dept. of Geomatics Engineering, Istanbul, Turkey \\ (yagmurn/tuzcuay/musaoglune/eerten @itu.edu.tr); ORCID 0000-0002-5915-6929, ORCID 0000-0003-2786-2033, \\ ORCID 0000-0002-8022-8755, ORCID 0000-0002-4208-7170, \\ ${ }^{2}$ ITU, Civil Engineering Faculty, Dept. of Environmental Engineering, Istanbul, Turkey (tanika@itu.edu.tr); ORCID \\ 0000-0002-0319-0298 \\ ${ }^{3}$ Gumushane University, Dept. of Geomatics Engineering, Gumushane, Turkey \\ (bbilgilioglu@ gumushane.edu.tr); ORCID 0000-0001-6950-4336
}

*Corresponding Author, Received: 26/10/2019, Accepted: 17/02/2020

\begin{abstract}
Remote sensing data provides great opportunities in various steps of watershed management like characterization of watersheds that bear dynamic structure with large land, monitoring the physical variations within the basin, and conducting various scenario analyses to detect the response of the basin. The high resolution capacity of today's satellite images enables the production of land use/cover data of a basin in shorter period of time. In this study, it is aimed to demonstrate various aspects of remote sensing technology to be used in watershed management studies. For that purpose, MODIS, Landsat and Sentinel satellite data with different spatial resolutions were used to monitor the surface water bodies in Konya Closed Basin (KCB) of Turkey. In addition, high spatial Worldview-3 satellite data were used to extract detailed information about Akgol Wetland located in KCB. A methodology was developed on the utilization of remote sensing technology consisting of 3 main groups; field surveys, satellite images and ancillary data. In the study, 5 different spectral indices were applied to Sentinel 2 data to determine the areas of surface water bodies. Moreover, Support Vector Machine (SVM) method was applied to Worldview-3 satellite image to classify Akgol Wetland and its vicinity. The importance of establishing watershed information system together with a database reflecting the characteristics of watersheds was underlined. Various examples were given from KCB that is known as the largest closed basin of the country with a surface area of 5.426 .480 ha. The basin owns 17 water bodies out of which 2 of them are RAMSAR sites. Within the scope of the study, information obtained from optical and synthetic aperture radar (SAR) satellite images in the basin were discussed. More accurate results were achieved by Sentinel 2 than MODIS and Landsat data. In addition, detailed information about the wetland were extracted by means of Worldview- 3 data and water bodies were monitored in all weather conditions via Sentinel 1 SAR data.
\end{abstract}

Keywords: Konya Closed Basin, MODIS, Sentinel, Landsat, Worldview- 3 


\section{INTRODUCTION}

Integrated watershed management has been internationally recognized as an important holistic approach towards natural resources management within the context of sustainable development. Countries have already accepted this understanding and great achievements have recently been realized in regard to conserving water, land and vegetation. The success of various management strategies developed so far depends on the establishment of a good/satisfactory database named as 'watershed information system' (Tanik, 2019). If the database formed stores the minimum data required to define the prevailing characteristics of the watershed of concern, it may further be utilized for various watershed analyses, terrain and/or water quality modelling, and for management of the overall basin (Randhir, 2007; EPA, 2008). Resource inventory required to characterize the watersheds covers the collection, analysis and presentation of data including the following components (UN, 1997);

- Topography and landform

- Geology and geomorphology

- Soils

- Climate

- Hydrology

- Ecology.

At this stage, Remote Sensing (RS) technology enables to generate spatial and temporal data of a number of physical attributes about the watershed surface that can be utilized to map the extent of land and water bodies at watershed scale, and to monitor their dynamics at regular and frequent time intervals (Huang et al., 2018). With the development of RS technology, it has become possible to achieve high resolution data. In order to extract information from satellite image data, different image processing techniques such as spectral indexes, pixel based and object-based classification can be used. Li et al. (2015) compared the performance of various MODIS derived indices to monitor spatiotemporal dynamics of hydrology in seasonally-flooded wetlands. Ludwig et al. (2019) identified suitable spectral indices sensitive to water and wetness using feature selection methods based on mutual information between optical indices and occurrence of water and wetness. Lamb et al. (2019) used spectral indexes and classification methods to determine the spatial extent and vegetation characteristics of tidal wetlands and their change by using Sentinel-1A, Phased Array type L-band Synthetic Aperture Radar (PALSAR), PALSAR-2, Sentinel-2A, and Landsat 8 imagery. Additionally, these methods can be utilized for different purposes such as mapping burned forest areas (Comert et al. 2019), classification of land use/land cover (Heumann, 2011). Comert et al. (2019) detected burned forest areas in Kumluca and Adrasan in Antalya, Turkey with $99 \%$ overall accuracy via using Landsat 8 data. Karakus et al. (2017) compared pixel-based and object-based classification techniques by using SPOT 5 data and similar results were obtained.

The objective of this study was to demonstrate the opportunities provided by RS data to be further applied in watershed management. Examples of data produced and/or processed by RS technology were given for Konya Closed Basin (KCB) of Turkey. It is important to note here that available and produced data were stored in the database of the watershed that formed the integral part of 'Watershed Information System'. Every basin has to bear an information system of its own, as each watershed has its intrinsic properties not similar to even the neighborhood basin.

\section{STUDY AREA}

KCB located at the Central Anatolia in Turkey has been declared as one of the 200 significant ecologically important regions of the world by the World Wildlife Foundation (WWF) (Dursun et al., 2012). It is located between $36^{\circ} 51^{\prime} \mathrm{N}$ and $39^{\circ} 29^{\prime} \mathrm{N}$ latitudes, $31^{\circ} 36^{\prime} \mathrm{E}$ and $34^{\circ} 52^{\prime} \mathrm{E}$ longitudes. It covers almost $7 \%$ of Turkey's overall surface area and bears an annual amount of 4,365 billion $\mathrm{m}^{3}$ of usable water. However, water consumption of 6,5 billion $\mathrm{m}^{3}$ in the basin points out that there is an annual water deficit of approximately 2 billion $\mathrm{m}^{3}$. Thus, this basin is known to be one of the significant basins of the country facing water scarcity problem. Semi-arid climatic conditions prevail in the basin. The average annual rainfall was around $407 \mathrm{~mm}$ taking into account the average of all years from 1923 to 2013. However, this annual precipitation value was found lower in this study that considered the 1984-2017 period. Larger surface areas of non-flowing water bodies with lower precipitation and higher evaporation are the significant characteristics of the basin compared to country's average meteorological status; however, the basin exerts an interesting water balance (CCIWR, 2016). It consists of only $2 \%$ of the country's overall surface water resources whereas involves $17 \%$ of the groundwater resources. As such, ' $\mathrm{KCB}$ is a basin that bears the minimum surface water resources while owning the highest groundwater resources' as depicted by DMP (2015). Agricultural areas cover almost 55.5\% of the basin followed by forests and semi-natural areas with $37.4 \%$ (CCIWR, 2016). The rest of land-use distribution is shared by urbanized areas and water surfaces. The region's agricultural production capacity has a strategic importance for Turkey's food supply, although KCB has the least amount of rainfall in the Central Anatolia (Celebi and Direk, 2017). KCB has a variety of surface water bodies as shown in Figure 1. Among the 17 water bodies 3 of them are lakes, whereas the rest are mainly wetlands of high ecological importance. 2 of them (Meke Maar and Kizoren Obrouk) have been declared as Ramsar sites. The area of each of these water bodies as well as their conservation status are given in Table 1.

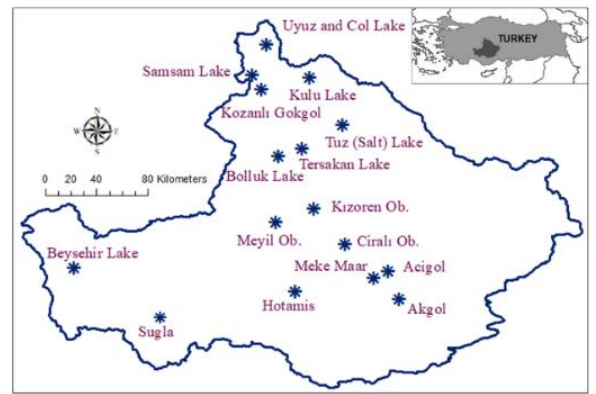

Figure.1 Geographical location of the surface water bodies in $\mathrm{KCB}$ 
Table 1 Surface water bodies of $\mathrm{KCB}$ and their conservation status (Forestry Statistics, 2010; Url 1)

\begin{tabular}{|c|c|c|}
\hline Name & $\begin{array}{c}\text { Area } \\
\text { (ha) }\end{array}$ & $\begin{array}{c}\text { Conservation } \\
\text { Status } \\
\end{array}$ \\
\hline Tuz Lake & 240000 & Natural Asset \\
\hline Beysehir Lake & 73000 & $\begin{array}{l}\text { Natural Asset } \\
\text { Natural Park }\end{array}$ \\
\hline Tersakan Lake & 11000 & Natural Asset \\
\hline Akgol Wetland & 5000 & $\begin{array}{l}\text { Natural Asset } \\
\text { Nature Reserve }\end{array}$ \\
\hline Bolluk Lake & 3800 & Natural Asset \\
\hline Hotamis & 5800 & - \\
\hline Kulu Lake & 1800 & Natural Asset \\
\hline Col Lake & 1500 & - \\
\hline Samsam Lake & 830 & Natural Asset \\
\hline Acigol & 400 & - \\
\hline Kozanli Gokgol & 650 & Natural Asset \\
\hline Meke Maar & 202 & $\begin{array}{c}\text { Natural Asset } \\
\text { Nature Park } \\
\text { Ramsar Site }\end{array}$ \\
\hline Kizoren Obrouk & 127 & Ramsar Site \\
\hline Cirali Obrouk & 100 & - \\
\hline Meyil Obrouk & 20 & - \\
\hline Uyuz Lake & 15 & Natural Asset \\
\hline
\end{tabular}

Musaoglu et al. (2018) conducted a long-term monitoring study of the wetlands in this basin via RS and Geographic Information System (GIS). The results derived indicated that the overall surface area of the water bodies in KCB decreased by approximately $23.5 \%$ within the inspection period of 1987-2017. One of the important wetlands of the basin named as Akgol Wetland has almost lost its water surface by $96 \%$ at the same time interval, and was in danger of extinction (Yagmur et al., 2018).

\section{DATA AND METHODOLOGY}

The flow diagram of the methodology developed specifically for this study is shown in Figure 2. The use of RS for KCB may be classified in 3 groups; field survey, satellite images, and ancillary data. Already available data and data produced within the scope of the study were placed under these 3 groups that formed the database of the basin. Data analyses were then realized with the gathered, produced and processed data stored in the database for watershed management. Apart from the methodology developed, ancillary data was also obtained during the site visits especially from the public authorities, regional institutions and more importantly, public advice and feedback were taken and utilized in the database formed. These details are not shown in the flow diagram of the methodology.

Field surveys consisted of spectroradiometer, GPS, levelling and thermal measurements; whereas, ancillary data was composed of watershed boundaries, meteorological data and digital elevation model (DEM) of the watershed. Optical and SAR images were both utilized. In this section, various examples on KCB will be presented under the available and produced data categories to enlighten the interested parties on the utilization and integration of RS in watershed management studies.

\subsection{Available data}

While conducting a study on a specific watershed, the primary work that should be realized is to delineate the watershed boundaries. It is important to fix the total area of concern at the beginning of the study. It is then that the topographical map of the watershed should be formed and illustrated in the form of DEM. Topography is an important component of resource inventory of a watershed. Figure 3 shows the example of DEM generated from SRTM for KCB.

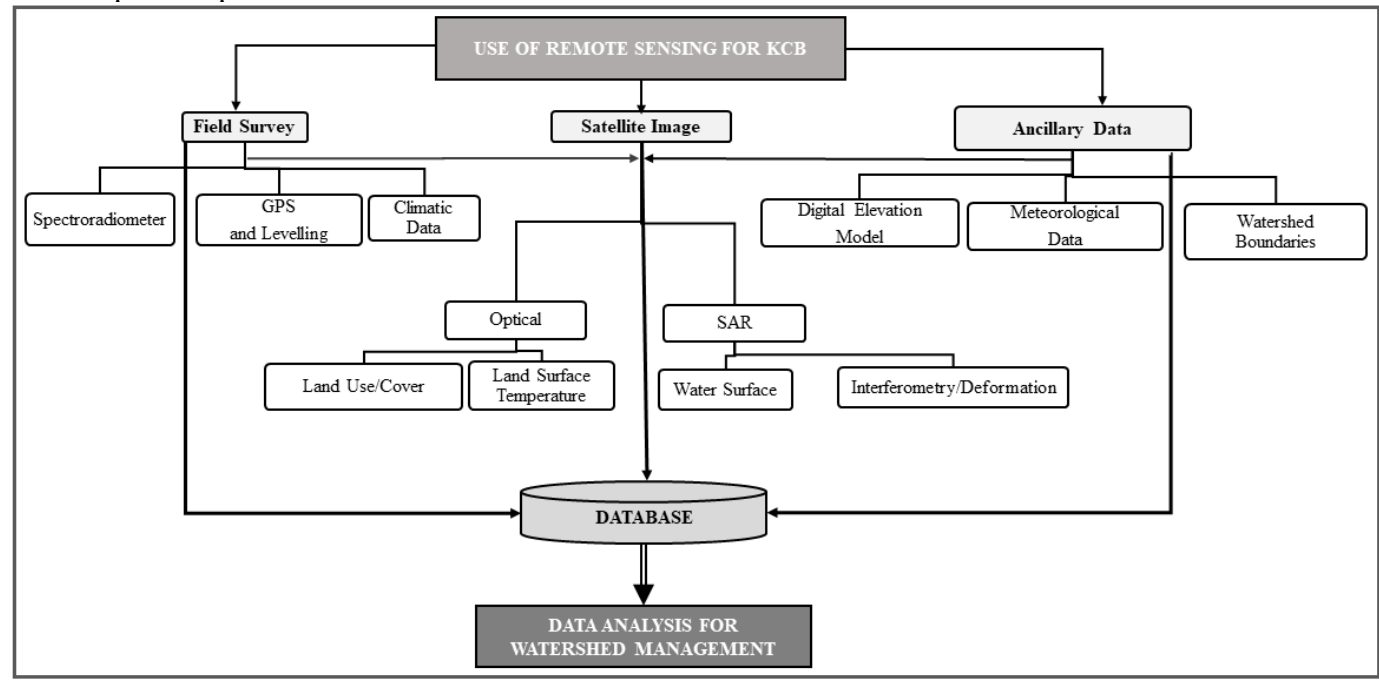

Figure.2 Flow chart of the methodology used 


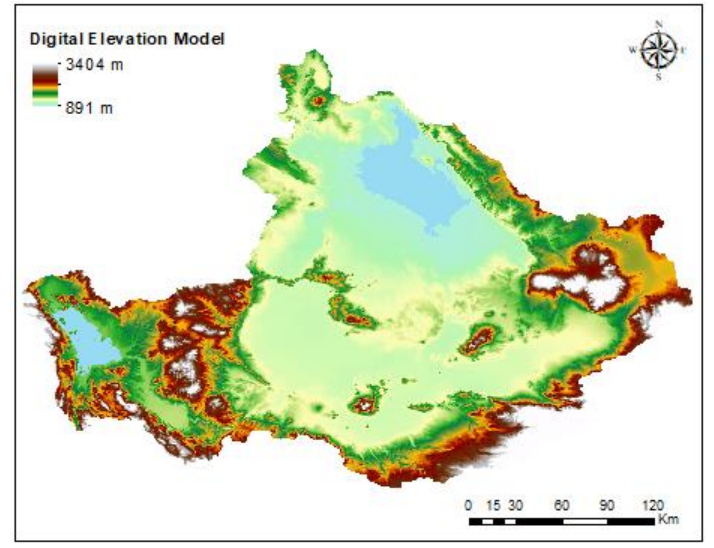

Figure.3 Digital Elevation Model (DEM) of KCB

The other available data that is of high importance in watershed management efforts is meteorological data including temperature, precipitation, evaporation, etc.

Required data were obtained from the nearest State Meteorological Station(s) representing the overall KCB. Figure 4 (a) and (b) demonstrate the long-term annual average temperature and precipitation values within the 1984-2017 period, respectively.

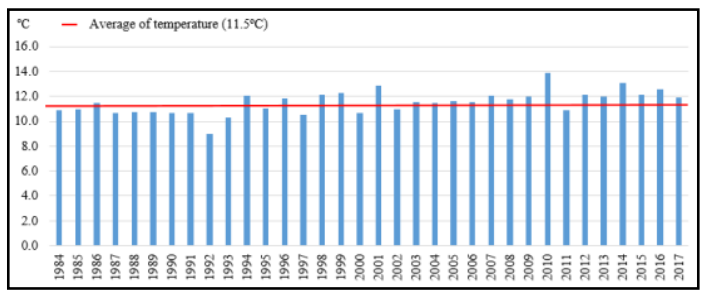

(a)

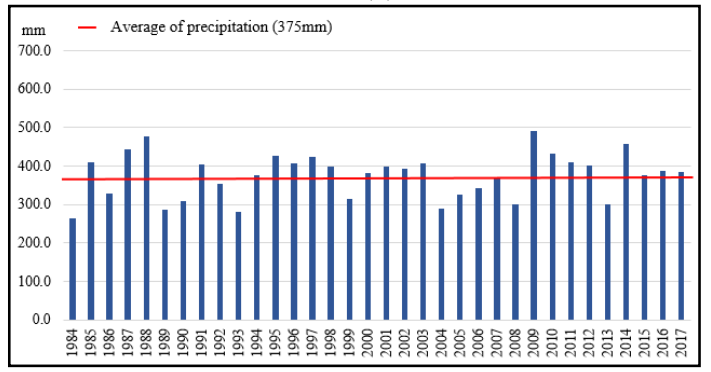

(b)

Figure.4 Long term annual average variation of (a) temperature and (b) precipitation values in $\mathrm{KCB}$

As $\mathrm{KCB}$ is known as one of the most important agricultural areas of Turkey; dams have been built and put into operation for supplying the irrigation demand of the basin. In general, the basin bears an arid/semi-arid climatic character; and thus, suffers from water resources on the contrary to its fertile soil characteristics. Most of the water streams/rivers get dry during summer. Therefore, dry and hot summers accelerate evaporation leading to more water loss. For example, excess evaporation causes the formation of salt layers of almost $30 \mathrm{~cm}$ thickness during summer in the Tuz (Salt) Lake and water loss of the lake was further compensated by diverting water of another nearby water body, and by discharging the treated domestic wastewaters of Konya
Province to the Lake via a main drainage channel. However, the situation in the 2 other systems, Meke Maar and Akgol Wetland was quite different. Water feeding and/or diversions from the other water resources have not been experienced so far leading to remarkable water losses. Areal values of the inspected water bodies were calculated from the satellite images at every 10 years interval between 1987-2017, whereas the meteorological data like temperature and precipitation were assessed starting from 1984. In the evaluation of the overall basin, data of the 12 meteorological stations existing in the basin were considered. However, only the nearby and representative ones were taken into consideration in discussing the climatic conditions of the individual water bodies. Meteorological data were gathered from the State Meteorological Service (SMS).

Hydrological condition of the watershed is also another important available data that can be depicted via RS. As referred in the introduction section, temporal and spatial assessments of water surfaces may be performed via satellite images belonging to various years. The areal values of water bodies are dynamic and are tend to change annually based on either natural and/or anthropogenic effects.

A noticeable areal change has occurred at Akgol Wetland, that is an internationally recognized water body of the basin, has almost lost its water surface by 96\% during a period of 30 years (1987-2017), and thus, it is in danger of extinction (Musaoglu et al., 2018). This finding was the outcome derived from the various satellite images used belonging to different years.

\subsection{Produced Data}

\subsubsection{Field Studies}

Field spectroscopy is usually used to reach the reflectance information of field spectra. Spectroradiometer and GPS receiver were used to collect samples during the field surveys. FieldSpec $\mathrm{HH}$ is the model of spectroradiometer used with 325-1075 $\mathrm{nm}$ spectral range. Position and spectral reflectance of one of the samples from water is given in Figure 5 together with site photos taken during the field surveys. Sample referred in Figure 5 was taken from shallow water of Akgol Wetland. When Figure 5 is examined in depth, it will be seen that the properties of spectral signature of water can be observed. It has high reflectance in green region, whereas low reflectance in the NIR region. The spectral reflectance of a water area changes according to its depth and amount of materials present (McCoy, 2005). 


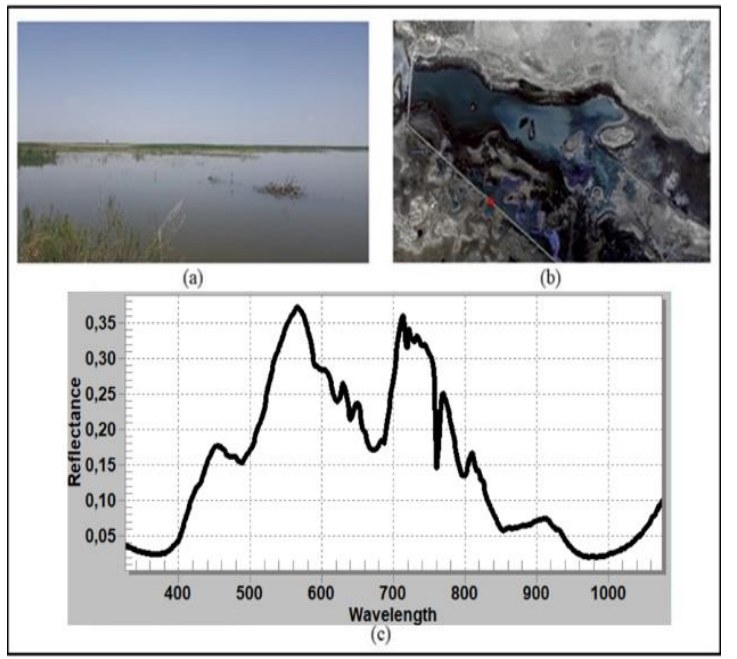

Figure.5 a) Water area, b) location of the water sample, c) spectral reflectance of the water sample

In addition, thermal measurements were also conducted in the study area with thermal thermometers providing extra data for evaluating the climatic condition of the basin. Produced LST from satellite images were also compared with field measurements (Sánchez-Aparicio et al., 2020).

Moreover, levelling at the basin was also carried out to calculate the accuracy of Sentinel 1 SAR interferometry results. During the field surveys, geometric levelling as one of the traditional measurement methods, was used to produce elevations in $\mathrm{mm}$ precision.

\subsubsection{Remote Sensing}

Resolution properties of satellite images enable information generation at different scales. It is possible to use different images based on the scale of the final product and on the required land-use/cover classes.

In this study, freely available MODIS, Landsat and Sentinel images were used for producing data at watershed with different scale. Moreover, Worldview-3 image was utilized to produce detailed information about Akgol Wetland. General characteristics of satellite images used and examples from different satellite images are given in Table 2 and Figure.6, respectively.
Table 2 Technical specifications of satellite data used

\begin{tabular}{|c|c|c|c|c|}
\hline Sat. & $\begin{array}{c}\text { Spatial } \\
\text { Res. }\end{array}$ & $\begin{array}{l}\text { Rad. } \\
\text { Res. }\end{array}$ & $\begin{array}{c}\text { Temp. } \\
\text { Res. }\end{array}$ & $\begin{array}{l}\text { Spectral Res. } \\
\quad(\mu \mathrm{m})\end{array}$ \\
\hline \multirow{5}{*}{$\stackrel{\tilde{\widetilde{O}}}{\Sigma}$} & 250m (bands 1 - & 12 & 16 & 36 bands: \\
\hline & 2) & bit & days & $1-19$ from 0.620 to \\
\hline & $500 \mathrm{~m}$ (bands $3-$ & & & 0.965 \\
\hline & 7) & & & $20-36$ from 3.66 to \\
\hline & $1000 \mathrm{~m}$ (bands $8-$ & & & 14.28 microns \\
\hline
\end{tabular}

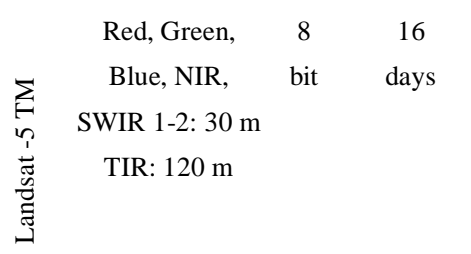

Red :0,63-0.69

Green :0,52-0.60

Blue :0,45-0.52

NIR :0,76-0.90

SWIR $1: 1.55-1.75$

SWIR $2: 2.08-2.35$

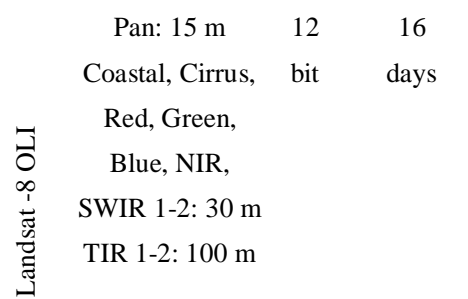

Red :0,636-0.673

Green :0,533-0.590

Blue :0,452-0.512

NIR :0,851-0.879

SWIR 1:1.566-1.651

SWIR 2:2.107-2.294

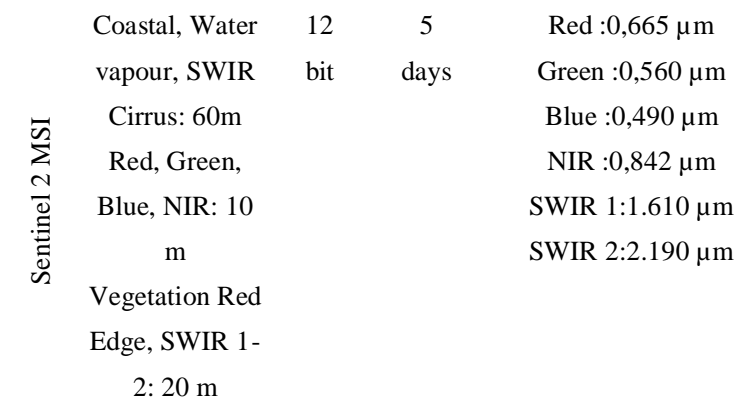

\begin{tabular}{|c|c|c|c|c|}
\hline \multirow{9}{*}{$\begin{array}{l}\frac{n}{3} \\
\frac{1}{3} \\
\frac{0}{3} \\
\frac{0}{0} \\
\frac{0}{3} \\
3\end{array}$} & \multirow{9}{*}{$\begin{array}{l}\text { Red, Red Edge, } \\
\text { Coastal, Green, } \\
\text { Yellow, Blue, } \\
\text { NIR 1-2: } 2 \text { m }\end{array}$} & 11 & & Coastal: $0.40-0.45$ \\
\hline & & bit & demand & Blue: $0.450-0.510$ \\
\hline & & & & Green: $0.510-0.580$ \\
\hline & & & & Yellow: $0.585-0.625$ \\
\hline & & & & Red: $0.630-0.690$ \\
\hline & & & & Red Edge: 0.705- \\
\hline & & & & 0.745 \\
\hline & & & & NIR 1: 0.770-0.895 \\
\hline & & & & NIR 2: 0.860-1.040 \\
\hline
\end{tabular}




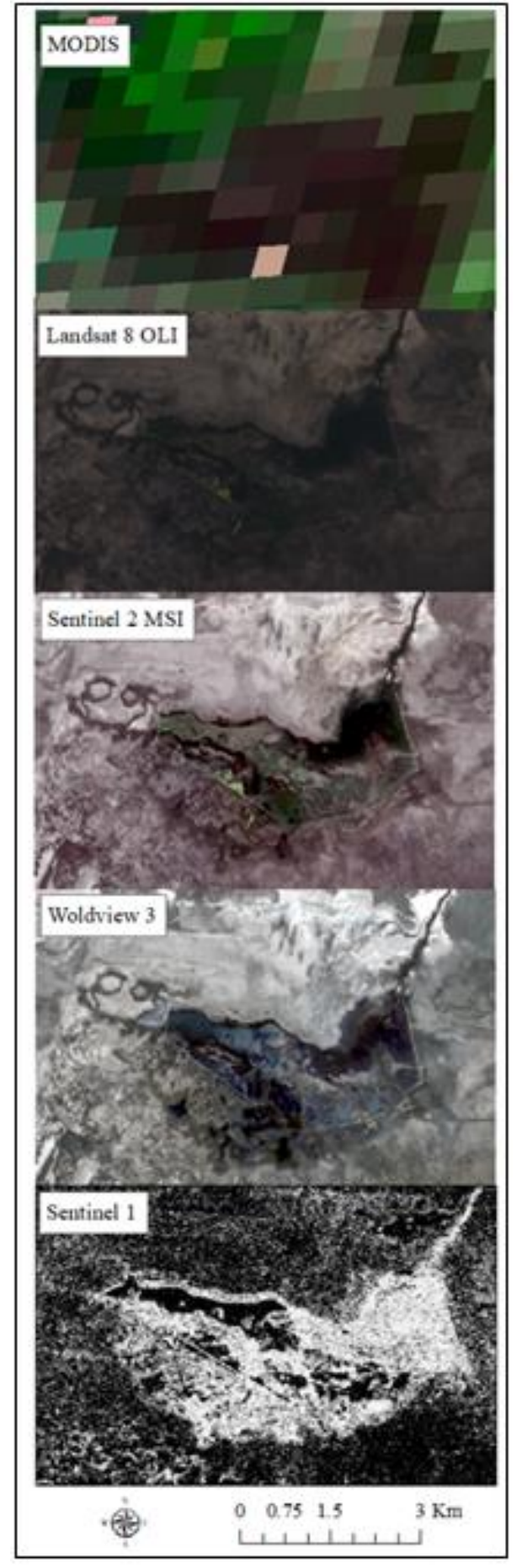

Figure.6 Satellite images used for Akgol Wetland

\subsection{Methodology}

\subsubsection{Spectral Indices}

Water surface area was calculated with Normalized Difference Water Index (NDWI). NDWI has been widely used for water body detection by Google Earth Engine software. Besides NDWI, there are various other water indices such as Modified NDWI, Automated Water Extraction Index (AWEI), and Water Ratio Index
(WRI) etc. as mentioned in Table 3. Indices use different spectral bands of satellite images. For instance, NDWI uses green and near infrared bands of the satellite image and results vary between (-1) and (1). If results are greater than zero, they indicate the water areas. MNDWI (Modified Normalized Difference Water Index) detect water areas by preventing noises originating from builtup areas, soil and vegetation $(\mathrm{Xu}, 2006)$. AWEInsh is a suitable index to extract water areas which are not affected by high shadow. However, AWEIsh is a proper index to detect water areas under shadow effect (Feyisa et al., 2014). In addition, water areas can be detected by using WRI (Water Ratio Index). The values of the index greater than 1 show water covered area (Shen and $\mathrm{Li}$, 2010).

Table 3. Spectral water indices used in this study

\begin{tabular}{ccc}
\hline Index & Formula & Reference \\
\hline NDWI & $\frac{(\text { Bgreen }- \text { Bnir })}{(\text { Bgreen }+ \text { Bnir })}$ & $\begin{array}{c}\text { Mcfeeters } \\
(1996)\end{array}$ \\
MNDWI & $\frac{(\text { Bgreen }- \text { Bswir })}{(\text { Bgreen }+ \text { Bswir })}$ & Xu (2006) \\
& Bblue $+2.5 \times$ Bgreen & \\
AWEIsh & $-1.5($ Bnir + Bswir1 $)-0.25$ & Feyisa et al. \\
& $\times$ Bswir2 & $(2014)$ \\
AWEInsh & $4 \times($ Bgreen - Bswir1) & Feyisa et al. \\
& $-(0.25 \times$ Bnir +2.75 & $(2014)$ \\
& $\times$ Bswir2 $)$ & Shen and Li \\
WRI & $\frac{(\text { Bgreen }+ \text { Bred })}{(\text { Bnir }+ \text { Bswir1 })}$ & $(2010)$ \\
& & \\
\hline
\end{tabular}

\subsubsection{Classification}

Worldview-3 satellite image, which has high spatial and spectral resolution, was used in classification to achieve detailed information. Six classes in the region; deep water, shallow water, vegetation, agricultural area, soil and saline soil were discriminated by Worldview-3 satellite image. For that purpose, support vector machine (SVM) method was used. SVM is a nonlinear method used to generate an optimum hyperplane in high dimensional feature space (Vapnik, 1999).

The spectral bands; coastal, blue, green, yellow, red, red edge, NIR1, and NIR2 of the satellite image were used as features to generate a model. Samples were divided into train and test with $\mathrm{K}$-fold cross validation method. In this method, the value of $\mathrm{K}$ parameter was chosen as 10 .

A radial basis kernel was selected as kernel type and there were two hyper-parameters which were cost and gamma. The hyper-parameters were detected by grid search method, which was suggested by Hsu et al (2003) to find optimal hyper-parameters. 


\subsubsection{SAR processing}

SAR images supply extended information about the physical properties more than the spectral properties of the earth. They can reflect the texture of the region. By using this feature of SAR images, surface water areas of lakes were automatically determined by using Google Engine. Sentinel-1 Ground Range Detected (GRD) products were calibrated by following the steps of thermal noise removal, radiometric calibration, terrain correction using digital elevation model, and converting backscatter values to decibels with Eq. 1.

$$
\sigma 0(\mathrm{~dB})=10 \times \log 10 \sigma^{0}
$$

Then, histogram-based image thresholding was applied on the image to extract water surface area.

\subsection{Results}

Five frequently used spectral indices shown in Table 3 were applied to Sentinel 2 image. Among these NDWI was selected as an example in this study. Therefore, it was applied to three different satellite images (MODIS, Landsat 8 and Sentinel 2). Figure 7 shows the results for $\mathrm{KCB}$ in 2018. Areal extents of the water bodies vary according to spatial resolution of the satellite images, and MODIS which has lower spatial resolution $(500 \mathrm{~m})$ showed lowest water area, whereas Sentinel 2 and Landsat 8 presented approximately the same water surface areas.

NDWI results of the Landsat images for overall KCB within years 1987-2017 is shown in Figure 8. It was seen that water surface area was decreased from 190517 ha to 134163 ha accounting to a decrease of approximately $30 \%$ between years 1987-2017. As such, the surface of water bodies varied from year to year, and this situation can be clearly observed from the multitemporal illustration. Similar maps enable the quantification of the water amounts leading to calculations on the water budget of each and/or overall surface water bodies in the basin. These calculations are further utilized by the experts working on watershed management.

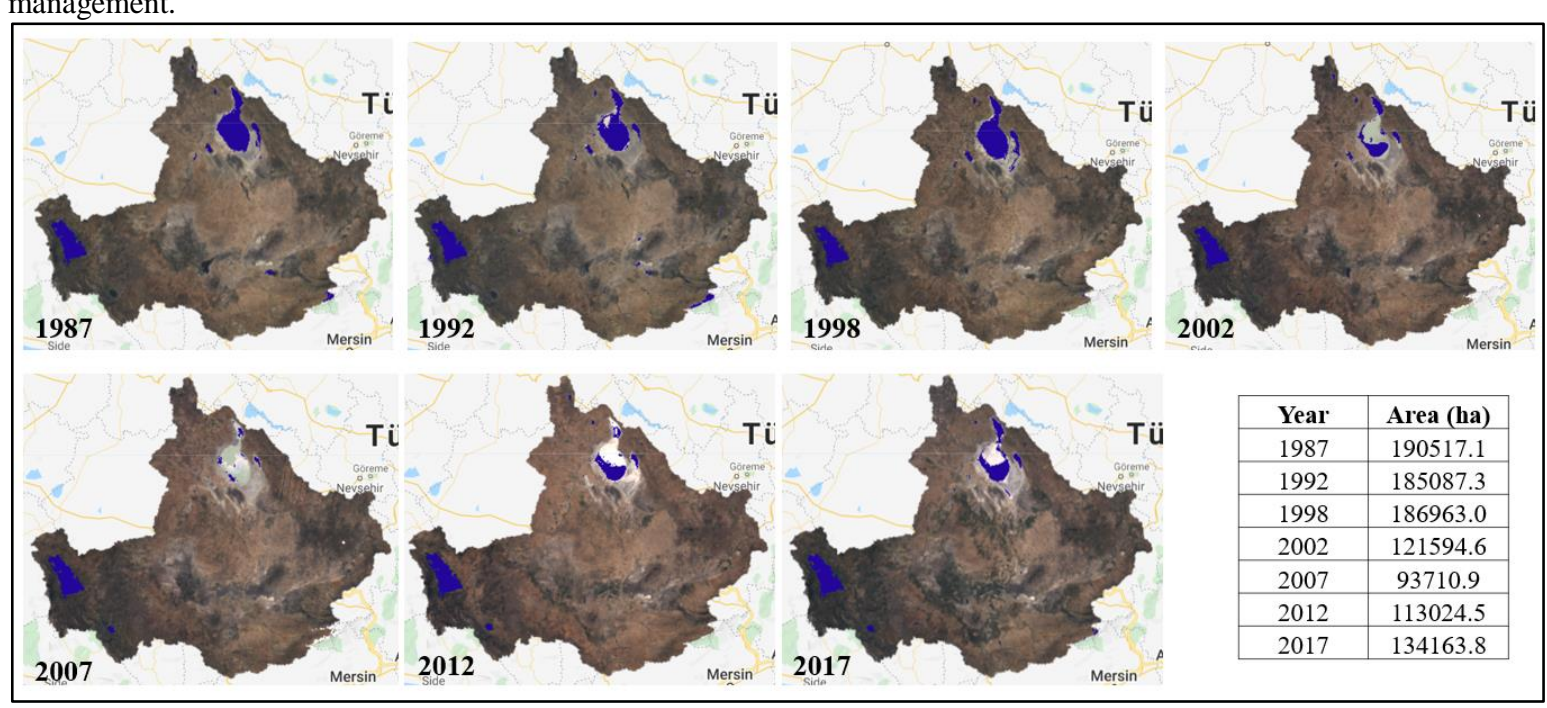

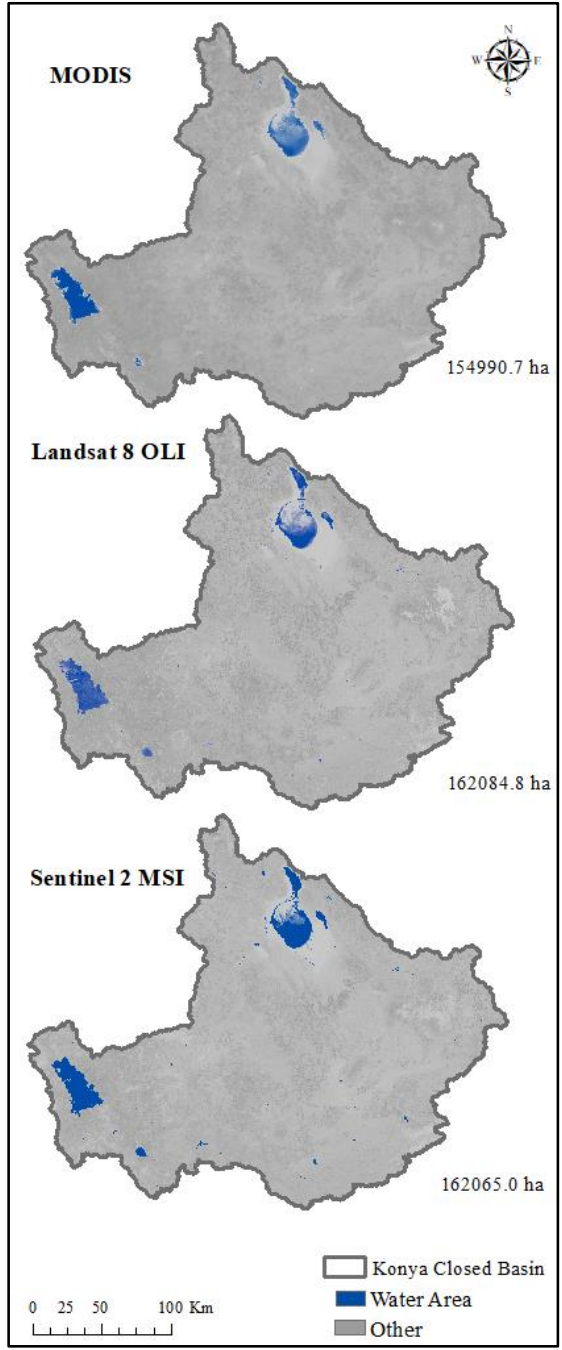

Figure.7 NDWI results of KCB with different satellite images

Figure.8 Long term changes of KCB between 1987-2017 
Thematic map produced from Worldview-3 with SVM classifier is shown in Figure 9. Error matrix were generated and test data was used to calculate the overall accuracy. Overall accuracy of the map produced from Worldview-3 with SVM classifier is $96 \%$ and is shown in the Figure 10.

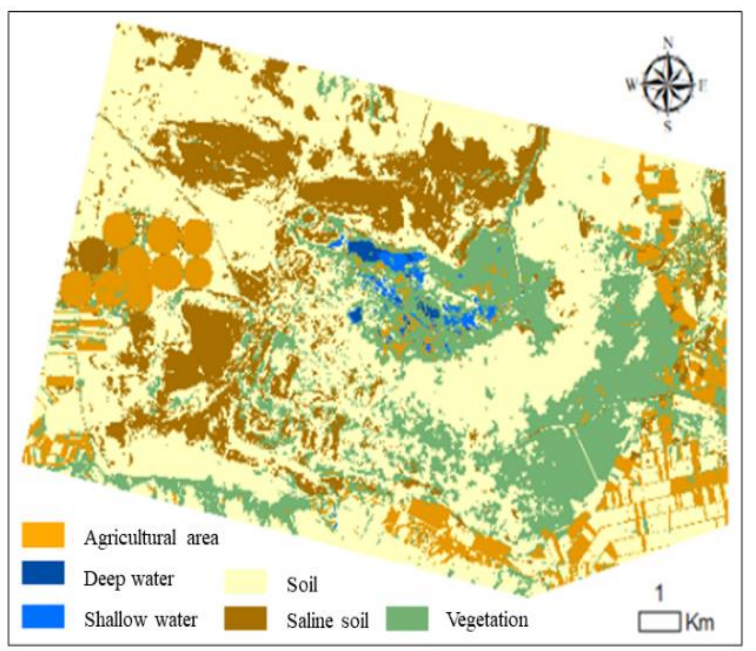

Figure.9 Thematic map produced from Worldview-3 with SVM classifier

\begin{tabular}{|l|c|c|c|c|c|c|c|}
\hline User Reference & Soil & Saline Soil & Vegetation & $\begin{array}{c}\text { Agricultural } \\
\text { area }\end{array}$ & $\begin{array}{c}\text { Shallow } \\
\text { water }\end{array}$ & Deep water & Sum \\
\hline Soil & 17805 & 0 & 0 & 7 & 320 & 0 & 18132 \\
\hline Saline soil & 455 & 6749 & 0 & 0 & 0 & 0 & 7204 \\
\hline Vegetation & 0 & 0 & 5877 & 18 & 0 & 0 & 5895 \\
\hline Agricultural area & 0 & 0 & 641 & 13873 & 0 & 0 & 14514 \\
\hline Shallow water & 0 & 0 & 0 & 0 & 7245 & 14 & 7259 \\
\hline Deep water & 0 & 0 & 0 & 0 & 829 & 8423 & 9252 \\
\hline Sum & 18260 & 6749 & 6518 & 13898 & 8394 & 8437 & \\
\hline Producer's accuracy & 0.975 & 1 & 0.902 & 0.998 & 0.863 & 0.998 & \\
\hline User's accuracy & 0.982 & 0.937 & 0.997 & 0.956 & 0.998 & 0.91 & \\
\hline
\end{tabular}

Figure.10 Accuracy assessment results of classification

The sample results obtained with this code for Tuz Lake are shown in Figure 9. Surface water area variations can be observed on monthly basis in this figure. Therefore, one can easily determine the changes that occurs within different time lags. Additionally, interferometry pairs were generated by using Sentinel-1 images to determine the vertical changes of the wetlands and their surroundings.

Example for Tuz Lake is given in Figure 10. When the interferometry results are compared with levelling, a high positive correlation of 0.90 is obtained. This figure puts forth the changes on the water depths on monthly basis. Thus, a high positive correlation (r: 0.73) was calculated from the results obtained via Figure 11 and 12.

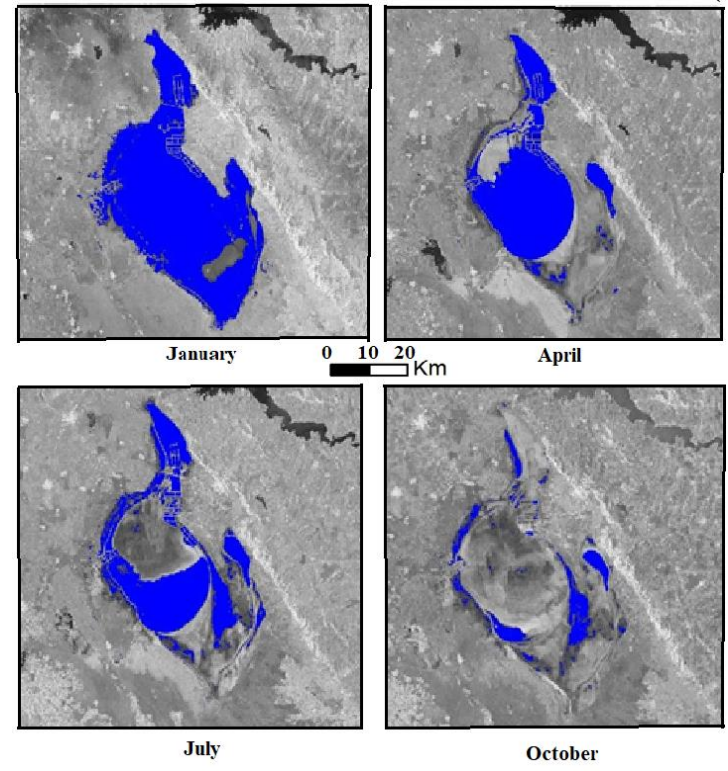

Figure.11 Monthly variations of recent water surfaces of Tuz Lake from Sentinel-1 SAR images (2018)

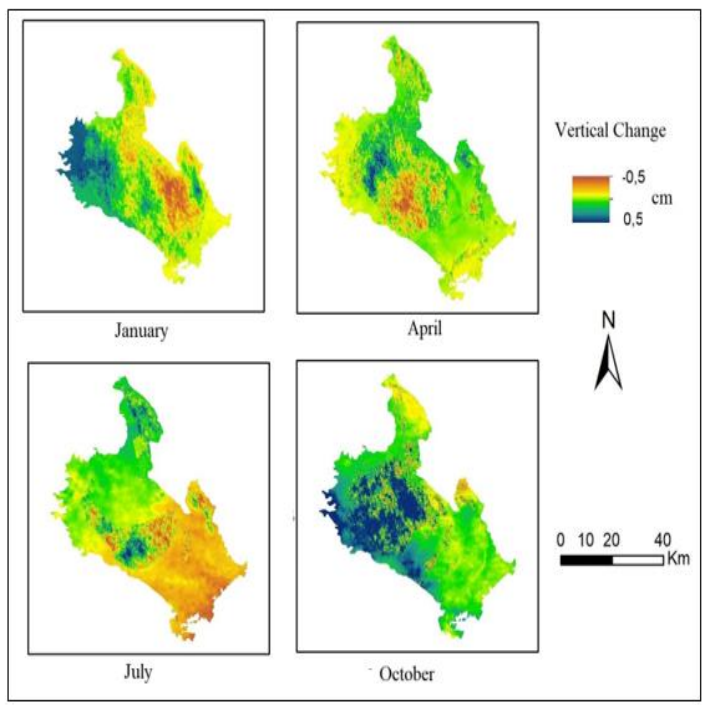

Figure.12 Vertical changes of Tuz Lake (2018)

\section{CONCLUSION}

As a conclusion, it can be stated that NDWI results of Sentinel 2 were more accurate than the others, especially MODIS because of its high spatial resolution. Landsat has been providing satellite images since 1970s. Therefore, it has been widely used for multi-temporal analysis. Besides Landsat, Sentinel 2 satellite image can also be used for watershed analysis that has higher resolution. For producing more detailed information, high resolution satellite image like Worldview-3 and classification algorithms can also be utilized. Sentinel 1 SAR images provide data under all weather conditions that is useful for seasonal monitoring.

Such integrated studies may be extended by adding the pollution criteria of both land and water bodies and by emphasizing on the social aspects of watershed 
management in future works. It is important to note here that watersheds have dynamic structures as humans always appear at the center and govern many of the changes detected via RS technology.

All the referred and mentioned data provided with the use of RS are then stored in the database established to the watershed of concern. Further quarries, analyses, modelling, scenario analyses and development of management strategies can be realized. Integration of RS technology in watershed studies has gained an everincreasing interest and highly favored by various disciplines.

\section{ACKNOWLEDGEMENTS}

The authors would like to acknowledge the financial support of the Scientific and Technological Research Council of Turkey under project number TUBITAK116Y142, and also Istanbul Technical University (ITU) Scientific Projects Office (BAP) under project number MGA-2017-40803 and MYL-2018-41650.

\section{REFERENCES}

CCIWR. (2016). Climate Change Impact on Water Resources Project, Ministry of Forestry and Water Affairs, General Directorate of Water Management [Online]. Date of access: 21/04/2018 http://iklim.ormansu.gov.tr/Eng/

Celebi, M. and Direk, M. (2017). Farmer behaviours and sustainable water management in semiarid Konya Closed Basin in Turkey. International Journal of Advanced Biological and Biomedical Research, 6(1), pp 441-450.

Comert, R, Matc1, D and Avdan, U (2019). Object based burned area mapping with random forest algorithm. International Journal of Engineering and Geosciences, 4 (2), 78-87. DOI: 10.26833/ijeg.455595

DMP. (2015). Konya Closed Basin Drought Management Plan Project, Ministry of Forestry and Water Affairs, General Directorate of Water Management. Date of access: 21/04/2018. http://www.suyonetimi.gov.tr.

Dursun, S., Onder, S., Acar, R., Direk, M. and Mucevher, O. (2012). Effect of environmental and socioeconomically change on agricultural production in Konya Region. Proceedings of International Conference on Applied Life Sciences (ICALS2012), Turkey, pp. 1936.

EPA. (2008). Handbook for developing watershed plans to restore and protect our waters, United States Environmental Protection Agency, Office of Water Nonpoint Source Control Branch Washington, DC. EPA 841-B-08-002, March 2008.

Feyisa, G.L., Meilby, H., Fensholt, R. and Proud, S.R. (2014). Automated water extraction index: a new technique for surface water mapping using Landsat imagery. Remote Sensing of Environment, 140, pp. $23-$ 35 .
Forestry Statistics (2010). A Publication of Official Statistics Programme, Republic of Turkey Ministry of Forestry and Water Affairs, Ankara.

Heumann, B. W. (2011). An object-based classification of mangroves using a hybrid decision tree-Support vector machine approach. Remote Sensing, 3(11), 24402460.

Hsu, C.W., Chang, C.c. and Lin, C.J. (2003). A practical guide to support vector classification, Technical Report. Department of Computer Science and Information Engineering, University of National Taiwan, Taipei, 112.

Huang, C., Chen, Y., Zhang, S. and Wu, J. (2018). Detecting, extracting, and monitoring surface water from space using optical sensors: A review. Reviews of Geophysics, 56 (2), pp. 333-360.

Karakus, P., Karabork., H and Kaya, S. (2017). A comparison of the classification accuracies in determining the land cover of Kadirli region of Turkey by using the pixel based and object based classification algorithms. International Journal of Engineering and Geosciences, 2 (2), 52-60.

Lamb, B.T, Tzortziou, M. A. and McDonald, K. C. (2019). Evaluation of Approaches for Mapping Tidal Wetlands of the Chesapeake and Delaware Bays, Remote Sensing, 11 (20), 2366.

Li, L., Vrieling, A., Skidmore, A., Wang, T., Muñoz, A. AND Turak, E. (2015). Evaluation of MODIS Spectral Indices for Monitoring Hydrological Dynamics of a Small, Seasonally-Flooded Wetland in Southern Spain, Wetlands, 35, 851-864.

Ludwig, C., Walli, A., Schleicher, C., Weichselbaum, J. and Riffler, M. (2019). A highly automated algorithm for wetland detection using multi-temporal optical satellite data, Remote Sensing of Environment, 224, 333-351.

McCoy, R. M. (2005). Field methods in remote sensing, pp. 42-114, ISBN: 1593850808, Guilford Press, New York

McFeeters, S. K. (1996). The use of the normalized difference water index (NDWI) in the delineation of open water features. International Journal of Remote Sensing, 17(7), pp. 1425-1432.

Musaoglu, N. Tanik, A., Gumusay, U.M., Dervisoglu, A., Bilgilioglu, B.B., Yagmur, N, Bakırman, T., Baran, D. and Gokdag, F, M. (2018). Long-term monitoring of wetlands via remote sensing and GIS: a case study from Turkey, 2nd International Conference on Climate Change, Sri Lanka, Colombo, 15-16 February 2018, Proceedings Vol. 2, p. 11-21.

Randhir, O.T. (2007). Watershed Management- Issues and Approaches, IWA publishing, London, UK, p. 146. 
Sánchez-Aparicio, M., Andrés-Anaya, P., Del Pozo, S. and Lagüela, S. 2020. Retrieving Land Surface Temperature from Satellite Imagery with a Novel Combined Strategy, 12, 277.

Shen, L. and Li, C. (2010), June. Water Body Extraction from Landsat ETM Imagery using Adaboost Algorithm. In Proceedings of the 18th International Conference on Geoinformatics, Beijing, China, pp. 1-4.

Tanik, A. (2019). Integrated watershed management. Lecture notes of CBM 546E graduate course at ITU Environmental Science, Engineering and Management Programme.

UN. (1997). Guidelines and manual on land-use planning and practices in watershed management and disaster reduction, United Nations, ST/ESCAP/1781, Economic and Social Commission for Asia and the Pacific, June 1997.

Url 1: http://www.kop.gov.tr/upload/dokumanlar/32.pdf (last accessed 1 April 2019)
Vapnik, V. (1999). The nature of statistical learning theory, pp. 133 - 140, ISBN: 0-387-98780-0, Springer science \& business media, New York, Berlin, Heidelberg

$\mathrm{Xu}, \mathrm{H}$. (2006). Modification of normalized difference water index (NDWI) to enhance open water features in remotely sensed imagery. International Journal of Remote Sensing, 27(14), pp. 3025-3033.

Yagmur, N., Bilgilioglu, B.B., Musaoglu, N., Erten, E. and Tanik, A. (2018). Temporal changes of lentic system surfaces in Konya Closed Basin, Turkey, 3. ICOCEE 2018, 3rd International Conference on Civil and Environmental Engineering, İzmir, 24-27 April 2018, Conference E-Book Vol.2., pp. 658-668. 